\title{
Checklist feasibility and impact in gastrointestinal endoscopy: a systematic review and narrative synthesis
}

\section{(1) $\odot \ominus$}

\section{Authors}

Véronique Bitar ${ }^{1}$, Myriam Martel ${ }^{2}$, Sophie Restellini' ${ }^{2,3}$, Alan Barkun², Omar Kherad ${ }^{4}$

Institutions

1 Division of Internal Medicine, Université de Montréal, Montreal, Canada

2 Division of Gastroenterology, McGill University, Montreal, Canada

3 Division of Gastroenterology, Geneva University Hospital and University of Geneva, Geneva, Switzerland

4 Department of Internal Medicine, La Tour Hospital and University of Geneva, Geneva, Switzerland

submitted 2.10 .2020

accepted after revision $\quad 28.10 .2020$

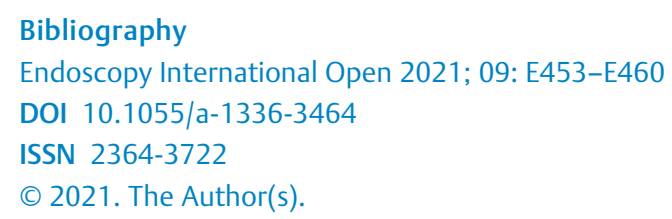
Commons Attribution-NonDerivative-NonCommercial License, permitting copying and reproduction so long as the original work is given appropriate credit. Contents may not be used for commecial purposes, or adapted, remixed, transformed or built upon. (https://creativecommons.org/licenses/by-nc-nd/4.0/)

Georg Thieme Verlag KG, Rüdigerstraße 14,

70469 Stuttgart, Germany

Corresponding author

Omar Kherad, MD, MPH, Division of Internal Medicine, Chief Quality Officer, Hôpital de la Tour and University of Geneva, 3 avenue Jean-Daniel Maillard, 1217 Geneva, Switzerland Fax: +41227196701

omar.kherad@latour.ch

Supplementary material is available under https://doi.org/10.1055/a-1336-3464

\begin{abstract}
Background and study aim Checklists prevent errors and have a positive impact on patient morbidity and mortality in surgical settings. Despite increasing use of checklists in gastrointestinal endoscopy units across many countries, a summary of cumulated experience is lacking. The aim of this study was to identify and evaluate the feasibility of successful checklist implementation in gastrointestinal endoscopy units and summarise the evidence of its impact on the commitment in safety culture.
\end{abstract}

Methods A comprehensive literature search was performed identifying the use of a checklist or time-out in endoscopy units from 1978 to January 2020 using OVID MEDLINE, EMBASE, and ISI Web of Knowledge databases, with search terms related to checklist and endoscopy. We summarised overall adherence to checklists from included studies through a narrative synthesis, characterizing barriers and facilitators according to nurse and physician perspectives, while also summarizing safety endpoints.

Results The seven studies selected from 673 screened citations were highly heterogeneous in terms of methodology, context, and outcomes. Across five of these, checklist adherence rates post-intervention varied for both nurses ( $84 \%$ to $96 \%$ ) and physicians (66\% to $95 \%$ ). Various facilitators (education, continued reassessment) and barriers (lack of safety culture, checklist completion time) were identified. Most studies did not report associations between checklist implementation and clinical outcomes, except for better team communication.

Conclusion Implementation of a gastrointestinal endoscopy checklist is feasible, with an understanding of relevant barriers and facilitators. Apart from a significant increase in the perception of team communication, evidence for a measurable impact attributable to gastrointestinal checklist implementation on endoscopic processes and safety outcomes is limited and warrants further study.

\section{Introduction}

Quality and safety are key issues in gastroenterology, driven by a common desire to promote best practices and to facilitate the implementation of evidence-based care for patients [1]. Quali- ty improvement (QI) initiatives have largely centered on gastrointestinal endoscopies that are widely used worldwide, due to the broadening of indications and the emergence of organized colorectal cancer screening programs across the world [2]. Despite significant improvements in technical aspects, gastroin- 
testinal endoscopy can be a challenging procedure associated with infrequent but serious complications [3,4]. QI projects may assist in reducing such complications, especially if the adverse events (AEs) stem from poor planning of the intervention rather than a lack in technical skills [4].

In accordance with the World Health Organization (WHO) Safe Surgery Saves Lives initiative, safety checklists have been proposed as a method of improving patient safety [5]. A landmark study confirmed that the surgical safety checklist reduced perioperative morbidity and mortality by routinely checking common safety issues, and by bettering team communication and dynamics [6]. Since then, compelling evidence about checklist utility has been published, highlighting their widespread adoption in different settings $[7,8]$, but only a few studies have addressed checklist implementation in a gastrointestinal endoscopy setting $[9,10]$. Several gastrointestinal societies have recognized the potential benefits of introducing a checklist before gastrointestinal endoscopic procedures [2]; however, there exists no guidance as to how best to implement such checklists or summary analyses that measure of utility. A better understanding of factors prohibiting or promoting checklist implementation in daily gastrointestinal endoscopy activities and its operationalization is vital to bridge the continuing gap between safety recommendations and frontline practice.

The purpose of this article was to evaluate the feasibility of successful checklist implementation in a gastrointestinal endoscopy unit, identify strategies to facilitate its implementation, and summarize the evidence of its impact on the commitment to a culture of safety. We also characterize the different components comprising an ideal endoscopy checklist and the corresponding implementation framework to drive change and help facilitate best practices in gastrointestinal endoscopy.

\section{Methods}

\section{Search strategy}

A comprehensive literature search was performed to identify the use of a checklist or time-out in the endoscopy unit from 1978 to January 2020 using OVID MEDLINE, EMBASE, and ISI Web of Knowledge databases, with search terms related to "checklist" and "endoscopy" (Appendix 1). Additional relevant studies were identified from cross-referencing and hand-searches of references of the retrieved articles. All fully published, human adult studies published in English or French were considered.

\section{Study selection and patient population}

We selected all observational studies that used a gastrointestinal endoscopic checklist. In this context, a checklist was defined as a set of key safety items concerning the patient's identity, particularity and the procedure that were verbally verified and shared with the whole team before the procedure with the aim of decreasing AEs and increasing patient safety. The checklist is also used to improve team communication, collaboration, and satisfaction. According to the WHO [5], the checklist identifies three phases of an intervention, each corresponding to a specific period in the normal flow of work: Before the intervention ("sign-in"), just before the procedure ("time-out") and before the patient leaves the operating/procedure room ("signout") [5]. We also considered the studies assessing only a "time out". We excluded studies focusing solely on sign-ins or sign-outs, as well as studies performed solely in a simulation setting. All studies assessing any patient undergoing a gastrointestinal endoscopic procedure were included.

\section{Outcome measures}

The primary outcomes of the study were the overall adherence rate to a checklist in a gastrointestinal endoscopy unit and the pertinent barriers and facilitators to its implementation according to endoscopy staff perspectives (nurses and physicians) using a narrative synthesis methodology [11]. As secondary outcomes, we evaluated the checklist impact on the commitment to a safety culture using team communication as a proxy, which has been proven to be a good indicator of quality and safety in health care [12]. In addition, we searched the literature for other safety outcomes such as completion rates, complications, and mortality.

\section{Validity assessment and data abstraction}

Two reviewers evaluated the eligibility of all identified citations independently (VB and OK) with a third resolving disagreements (AB). Study quality was assessed using the Ottawa-Newcastle criteria for observational studies [13].

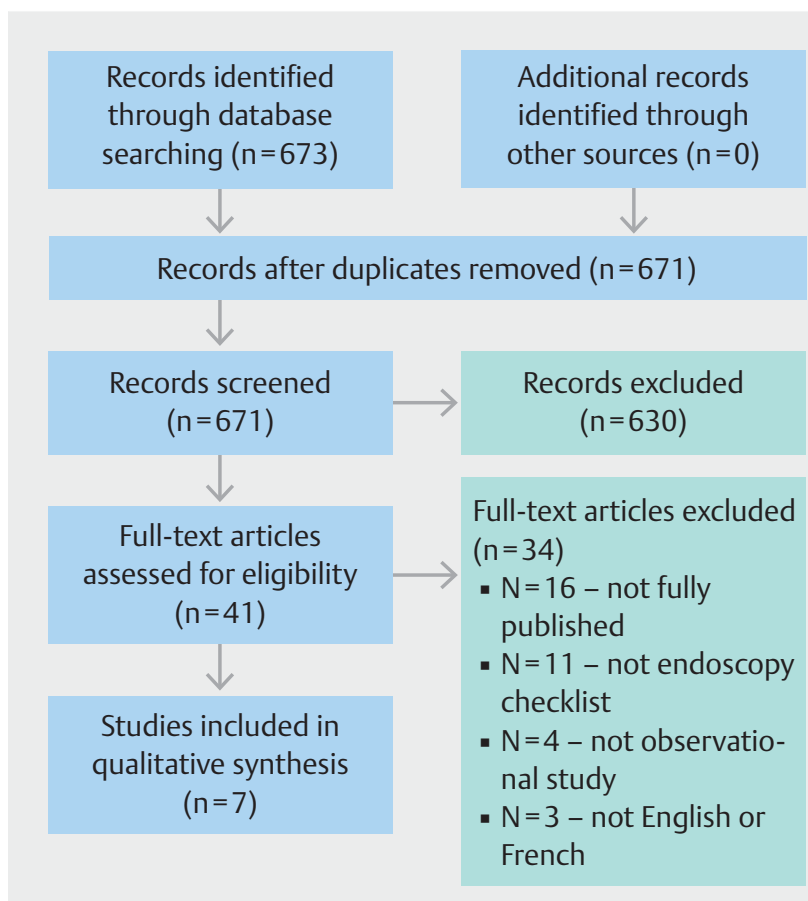

Fig. 1 Prisma diagram 


\section{Results}

A total of 673 citations were identified for a total of 671 after exclusion of duplicates. After review, seven articles were included in our study ( $\triangleright$ Fig. 1 and $>$ Table 1 ) $[9,10,14-18]$.

\section{Adherence to the checklist}

Five studies assessed adherence to the checklist in a gastrointestinal endoscopy unit setting; only four performed a prepost intervention compliance rate analysis (- Fig. 2 ). In those studies, baseline compliance before any intervention varied from $0 \%$ to $93 \%$ and $0 \%$ to $70 \%$ for nurses and physicians respectively. Post-intervention, nurse adherence rates to checklists varied from $84 \%$ to $96 \%$, and physician rates from $66 \%$ to $95 \%$ with a mean improvement post-intervention of $44 \%$ and $46 \%$ in nurse and physician adherence rates, respectively. As depicted in $\mathbf{F i g . 2}$, rates of nurse adherence to the checklist were higher than physician adherence rates in the two studies where pre/post-implementation compliances were measured. Different implementation strategies were used in those studies. Most focused on educational lectures to frontline staff about patient safety culture and checklist utility. Notably, Raphael et al. [17] tried to improve rates of compliance with the checklist by using remote video auditing (RVA). This intervention consists of installation of cameras in every endoscopic room to monitor compliance and application of the time-out in order to collect data but also to encourage the team to complete the checklist appropriately. Other interventions were used, such as educational emails to the endoscopic team members with visual reminders highlighting the importance of the checklist and its completion [16].

- Table1 Description of the included studies.

\begin{tabular}{|c|c|c|c|c|c|c|}
\hline $\begin{array}{l}\text { Authors, } \\
\text { date and } \\
\text { country }\end{array}$ & Name & Size & $\begin{array}{l}\text { Study } \\
\text { design }\end{array}$ & Intervention & Outcomes & Results \\
\hline $\begin{array}{l}\text { Coriat, } \\
2009, \\
\text { France } \\
{[15]}\end{array}$ & $\begin{array}{l}\text { Quality con- } \\
\text { trol of colo- } \\
\text { noscopy pro- } \\
\text { cedures: A } \\
\text { prospective } \\
\text { validated } \\
\text { method for } \\
\text { the evaluation } \\
\text { of professional } \\
\text { practices ap- } \\
\text { plicable to all } \\
\text { endoscopic } \\
\text { units }\end{array}$ & 200 procedures & $\begin{array}{l}\text { Observa- } \\
\text { tional pro- } \\
\text { spective } \\
\text { study }\end{array}$ & $\begin{array}{l}\text { Introduction of a } \\
\text { prospectively de- } \\
\text { veloped checklist of } \\
\text { quality-control } \\
\text { items covering ev- } \\
\text { ery phase of colo- } \\
\text { noscopy }\end{array}$ & $\begin{array}{l}\text { Checklist completion } \\
\text { rate } \\
\text { Procedure appropri- } \\
\text { ateness } \\
\text { Colonic preparation } \\
\text { Colonoscopy com- } \\
\text { pletion rate } \\
\text { Identification of ade- } \\
\text { nomas and carcino- } \\
\text { mas per colonoscopy }\end{array}$ & $\begin{array}{l}\text { The checklist was complete } \\
\text { for } 57 \% \text { of the colonosco- } \\
\text { pies } \\
\text { Indications for colonoscopy } \\
\text { was appropriate in } 94 \% \text { of } \\
\text { cases } \\
\text { Insufficient colonic prepa- } \\
\text { ration in } 9 \% \text { of procedures } \\
93 \% \text { of colonoscopies were } \\
\text { completed } \\
\text { Identification of } 0,38 \text { and } \\
0,045 \text { carcinoma per colo- } \\
\text { noscopy }\end{array}$ \\
\hline $\begin{array}{l}\text { Coriat, } \\
2012, \\
\text { France } \\
{[14]}\end{array}$ & $\begin{array}{l}\text { Quality Indica- } \\
\text { tors for Colo- } \\
\text { noscopy Pro- } \\
\text { cedures: A } \\
\text { Prospective } \\
\text { Multicentre } \\
\text { Method for } \\
\text { Endoscopy } \\
\text { Units }\end{array}$ & $\begin{array}{l}2000 \text { proce- } \\
\text { dures }\end{array}$ & $\begin{array}{l}\text { Observa- } \\
\text { tional pro- } \\
\text { spective } \\
\text { sudy }\end{array}$ & $\begin{array}{l}\text { Introduction of a } 10 \\
\text { quality-control in- } \\
\text { dicators checklist }\end{array}$ & $\begin{array}{l}\text { Validity of the colo- } \\
\text { noscopy indication } \\
\text { Colonic preparation } \\
\text { Colonoscopy com- } \\
\text { pletion rate } \\
\text { Adenoma detection } \\
\text { rate per colonoscopy }\end{array}$ & $\begin{array}{l}\text { Valid indication for colo- } \\
\text { noscopy in } 96 \% \text { of cases } \\
\text { Insufficient colonic prepa- } \\
\text { ration in } 4 \% \text { of procedures } \\
95 \% \text { of colonoscopies were } \\
\text { completed } \\
\text { Adenoma detection rate } \\
\text { was } 0,31 \text { per successful co- } \\
\text { lonoscopy }\end{array}$ \\
\hline $\begin{array}{l}\text { Dubois, } \\
2017, \\
\text { Sweden } \\
{[9]}\end{array}$ & $\begin{array}{l}\text { Person-cen- } \\
\text { tered endos- } \\
\text { copy safety } \\
\text { checklist: De- } \\
\text { velopment, } \\
\text { implementa- } \\
\text { tion, and eval- } \\
\text { uation }\end{array}$ & $\begin{array}{l}\text { Team mem- } \\
\text { bers } \\
\text { Baseline: } n=27 \\
4 \text { months } n=20 \\
6 \text { months } n=10 \\
10 \text { months } n= \\
15 \\
\text { Patients Base- } \\
\text { line: } 168 \text { Fol- } \\
\text { low-up: } 185\end{array}$ & $\begin{array}{l}\text { Pre-post } \\
\text { study }\end{array}$ & $\begin{array}{l}\text { Development and } \\
\text { implementation of } \\
\text { an endoscopy } \\
\text { checklist } \\
\text { Checklist introduc- } \\
\text { tion seminars and } \\
\text { team training ses- } \\
\text { sions mandatory for } \\
\text { all endoscopy staff }\end{array}$ & $\begin{array}{l}\text { Identity verifications } \\
\text { of patients } \\
\text { Adherence to the } \\
\text { checklist } \\
\text { Staff satisfaction } \\
\text { Patient satisfaction }\end{array}$ & $\begin{array}{l}\text { Significant increase in iden- } \\
\text { tity verification of patients } \\
\text { by the physician ( } 0 \% \text { at } \\
\text { baseline to } 87 \% \text { after } 10 \\
\text { months) and remained high } \\
\text { among nurses ( } 93 \% \text { at } \\
\text { baseline to } 96 \% \text { after } 10 \\
\text { months) } \\
\text { All parts of the timeout } \\
\text { were included in } 56 \% \text { of the } \\
\text { observation } \\
\text { No significant improvement } \\
\text { concerning staff or patient } \\
\text { satisfaction }\end{array}$ \\
\hline
\end{tabular}


- Table 1 (Continuation)

\begin{tabular}{|c|c|c|c|c|c|c|}
\hline $\begin{array}{l}\text { Authors, } \\
\text { date and } \\
\text { country }\end{array}$ & Name & Size & $\begin{array}{l}\text { Study } \\
\text { design }\end{array}$ & Intervention & Outcomes & Results \\
\hline $\begin{array}{l}\text { Kherad, } \\
\text { 2018, Ca- } \\
\text { nada [10] }\end{array}$ & $\begin{array}{l}\text { Implementa- } \\
\text { tion of a } \\
\text { checklist be- } \\
\text { fore colonos- } \\
\text { copy: a quality } \\
\text { improvement } \\
\text { initiative }\end{array}$ & $\begin{array}{l}\text { Procedures } \\
\text { Baseline: } 1317 \\
\text { Comparative: } \\
1141 \\
\text { Questionnaires } \\
\text { Staff } \\
\text { Baseline : } 24 \\
\text { Comparative : } \\
22 \\
\text { Patients } \\
\text { Baseline : } 147 \\
\text { Comparative : } \\
121\end{array}$ & $\begin{array}{l}\text { Observa- } \\
\text { tional } \\
\text { study }\end{array}$ & $\begin{array}{l}\text { Development and } \\
\text { implementation of } \\
\text { an endoscopy } \\
\text { checklist } \\
\text { Staff education }\end{array}$ & $\begin{array}{l}\text { Primary outcomes } \\
\text { Team satisfaction } \\
\text { Patient satisaction } \\
\text { Secondary out- } \\
\text { comes } \\
\text { Team perception } \\
\text { about the checklist } \\
\text { Colonoscopy com- } \\
\text { pletion rate } \\
\text { Per-procedural com- } \\
\text { plications } \\
\text { Rate of sedation } \\
\text { Adequate histologi- } \\
\text { cal labeling manage- } \\
\text { ment } \\
\text { Explicit recording of } \\
\text { follow-up recom- } \\
\text { mendations }\end{array}$ & $\begin{array}{l}\text { Full completion of the che- } \\
\text { clist in } 69 \% \text { of cases } \\
\text { Perception of team com- } \\
\text { munication and teamwork } \\
\text { was improved after check- } \\
\text { list introduction } \\
\text { No significant impact on the } \\
\text { other outcomes evaluated }\end{array}$ \\
\hline $\begin{array}{l}\text { Matharoo, } \\
\text { 2015, Eng- } \\
\text { land [16] }\end{array}$ & $\begin{array}{l}\text { The endos- } \\
\text { copy safety } \\
\text { checklist : A } \\
\text { longitudinal } \\
\text { study of fac- } \\
\text { tors affecting } \\
\text { compliance in } \\
\text { a tertiary re- } \\
\text { ferral centre } \\
\text { within the Uni- } \\
\text { ted Kingdom }\end{array}$ & $\begin{array}{l}\text { Baseline : } 199 \\
\text { procedures } \\
\text { Comparative : } \\
151 \text { procedures }\end{array}$ & $\begin{array}{l}\text { Pre-post } \\
\text { study }\end{array}$ & $\begin{array}{l}\text { Team education } \\
\text { and training } \\
\text { Electronic and } \\
\text { physical reminders } \\
\text { Mandating the use } \\
\text { of the checklist as } \\
\text { part of hospital pol- } \\
\text { icy } \\
\text { Senior leadership } \\
\text { Targeted feedback }\end{array}$ & $\begin{array}{l}\text { Checklist compliance } \\
\text { rate } \\
\text { Factors affecting } \\
\text { checklist compliance } \\
\text { rate }\end{array}$ & $\begin{array}{l}\text { Significant increase in } \\
\text { checklist completion rate } \\
\text { (53\% to 66\%) } \\
\text { Factors associated with } \\
\text { greater checklist compli- } \\
\text { ance included morning pro- } \\
\text { cedures, consultant or nur- } \\
\text { ses-led procedures, as well } \\
\text { as those conducted in the } \\
\text { bowel cancer screening } \\
\text { program }\end{array}$ \\
\hline
\end{tabular}

\section{Factors driving adherence to the gastrointestinal endoscopy checklist}

Many barriers and facilitators driving adherence to the checklist were identified ( $>$ Table 2 ). Raphael et al. identified four barriers limiting compliance to the endoscopic checklist: lack of leadership, inconsistent documentation of the time-out process, irrelevant safety checklist items, and lack of a patient safety culture [17]. Kherad et al. in turn identified as barriers the time required to complete the checklist, loss of physician autonomy, and fear of accentuating patient anxiety [10].

To overcome such barriers, authors have suggested several strategies that could facilitate incorporation of the checklist into their daily routine: four groups have suggested a permanent endoscopic team education about quality control, instituting a strong patient safety culture, and demonstrating to users the utility of the checklist $[10,13,15-17]$. Furthermore, Raphael et al. identified additional implementation facilitators such as integration of a time-out leader, creation of a concise endoscopy-specific safety checklist, and incorporation of a visual indication of a completed time-out process [17]. Other facilitators are listed in $>$ Table 2.

\section{Safety and clinical outcomes}

Of the seven included articles, only three collected data on safety and clinical outcomes pre-post checklist implementation ( $\triangleright$ Table 3) $[9,10,18]$. Significant improvements were noted in teamwork and team communication ( $4.36 \pm 0.78$ vs. $3.79 \pm 1.0$; $P=0.04)$ [10], with a trend towards better quality in collaboration with nurses $(P=0.07)$ [9].

Although patient perception of teamwork and team communication was also improved following checklist implementation (4.63 \pm 0.59 vs. $4.85 \pm 0.36 ; P=0.03$ ) [10], some patients complained they had to answer the same questions several times while in the endoscopy room $(P=0.01)$ [9].

Kherad et al. concluded that almost two-thirds of staff members (59\%) thought patient safety improved following checklist implementation. Wittren et al. also reported that $57 \%$ of nurses believed the checklist contributed to safe patient care [18].

Furthermore, additional benefits have included reduced procedural delays according to 11 nurses (79\%), improved unit efficiency, an increase in the number of patients arriving correctly prepared for their procedure [18], and an increase in identity checks performed by the physicians (from $0 \%$ at baseline to $87 \%$ after 10 months, $P<0.001$ ) [9]. Wittren et al. even demonstrated an additional 19 procedures added to the sche- 


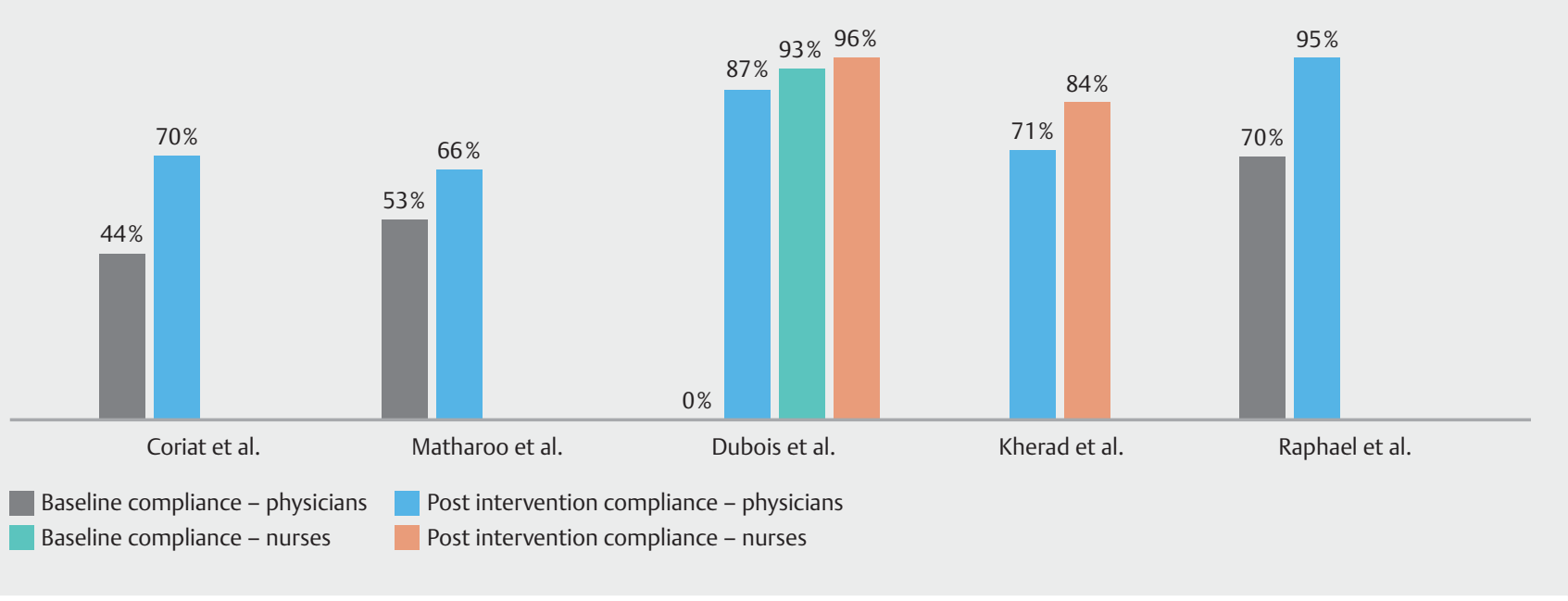

Fig. 2 Pre-post intervention compliance with a gastrointestinal endoscopy checklist.

- Table 2 Factors driving compliance with the gastrointestinal endoscopy checklist.

\begin{tabular}{|c|c|}
\hline Barriers & Facilitators \\
\hline $\begin{array}{l}\text { Lack of patient safety } \\
\text { culture }\end{array}$ & $\begin{array}{l}\text { Formal education of the entire endos- } \\
\text { copy team on quality control and } \\
\text { safety culture }\end{array}$ \\
\hline Patient anxiety & Morning procedures \\
\hline $\begin{array}{l}\text { Time required to complete } \\
\text { the checklist }\end{array}$ & Continued re-assessment \\
\hline Additional unjustified time & Targeted feedback \\
\hline Loss of autonomy & Senior leadership \\
\hline $\begin{array}{l}\text { Lack of designated team } \\
\text { member to lead time-out } \\
\text { process }\end{array}$ & $\begin{array}{l}\text { Designation of a time-out process } \\
\text { leader }\end{array}$ \\
\hline \multirow{4}{*}{$\begin{array}{l}\text { Irrelevant safety checklist } \\
\text { items not applicable to } \\
\text { endoscopic procedures }\end{array}$} & Consultant or nurse-led procedures \\
\hline & $\begin{array}{l}\text { Procedures conducted in the bowel } \\
\text { cancer screening program }\end{array}$ \\
\hline & $\begin{array}{l}\text { Visual indication of initiation of the } \\
\text { time-out process }\end{array}$ \\
\hline & $\begin{array}{l}\text { Creation of a concise endoscopy- } \\
\text { specific safety checklist }\end{array}$ \\
\hline
\end{tabular}

dule and completed during the pilot study, suggesting a $21 \%$ total increase in endoscopy procedure completion [18].

\section{Discussion}

For the past two decades, there has been a growing interest on how to prevent errors from occurring in healthcare delivery. Checklists have been proposed as a method of improving patient safety by routinely checking common operational procedures, and by improving team communication and dynamics.
In establishing a standardized procedure, checklists lessen reliance on memory and thus reduce errors of omission [19]. Checklists have become standard of care in different practices, mainly in surgical specialties, but also in acute care, such as in emergency department [8]. In intensive care units, Pronovost et al. have even proven that incidence of catheter-bloodstream infection can be reduced by $66 \%$ with implementation of a checklist [20].

Our analysis, based on five studies [9,10,15-17], confirms that gastrointestinal endoscopy setting is no exception and supports the feasibility of successful checklist adoption in this specific setting. However, implementation of safety checklists is highly variable with heterogenous adherence rates among frontline staff, varying from $84 \%$ to $96 \%$ for nurses and $66 \%$ to $95 \%$ for physicians $[9,10,15-17]$. Nurses and physicians identified many barriers to checklist implementation, such as time delay, lack of patient safety culture, and lack of leadership ( Table 1). Moreover, perceptions of different quality initiatives usually differ between nurses and physicians. Additional unjustified time and loss of autonomy are often reported as the main hurdles for physicians [19]. This is reflected by a lower adherence rate among physicians (66\% to $95 \%$ ), who were more reluctant to complete the checklist than were nurses ( $84 \%$ to $96 \%$ ). Those barriers are extremely similar to the ones identified in relation to the WHO surgical checklist [21].

As in any medical fields, change management in safety culture is challenging and may face significant resistance. Ramanujam et al. described three barriers to change: senior physicians are often at a distance of routine patient care and are thus unaware of the extent to which patients are exposed to errors; clinicians give importance mainly to errors leading to serious but rare AEs and hence do not see the need for change; and finally, some staff members can see some of the proposed change, such as increasing communication with the multidisciplinary team, as inappropriate and unnecessary for improving patient safety [22]. Similarly, the biggest challenge in implementation of the surgical checklist was clinicians' negative attitude and lack of clinician engagement [19]. 
- Table 3 Outcomes post-implementation of a gastrointestinal endoscopy checklist.

\begin{tabular}{|l|l|l|l|}
\hline Team satisfaction & Patient satisfaction & Security & Others \\
\hline $\begin{array}{l}\text { Increased quality in collaboration } \\
\text { with nurses [9] }\end{array}$ & $\begin{array}{l}\text { Patients noticed they had to answer } \\
\text { the same questions several times } \\
\text { while in the examination room [9] }\end{array}$ & $\begin{array}{l}\text { Almost two-thirds of staff } \\
\text { members thought safety } \\
\text { was improved [9] }\end{array}$ & $\begin{array}{l}\text { Increase in identity checks per- } \\
\text { formed by the physicians [9] }\end{array}$ \\
\hline $\begin{array}{l}\text { Increased perception of the impor- } \\
\text { tance of patient participation [9] }\end{array}$ & $\begin{array}{l}\text { Patient perception of team commu- } \\
\text { nication and teamwork was im- } \\
\text { proved after checklist implementa- } \\
\text { tion [10] }\end{array}$ & $\begin{array}{l}\text { More than half of nurses } \\
\text { agreed that the checklist } \\
\text { contributed to safe patient } \\
\text { care [18] }\end{array}$ & $\begin{array}{l}\text { Improved efficiency in the unit and } \\
\text { increased the number of patients } \\
\text { who arrived prepared for their pro- } \\
\text { cedures [18] }\end{array}$ \\
\hline $\begin{array}{l}\text { Teamwork and team communica- } \\
\text { tion perception was improved } \\
\text { compared with baseline [10,18] }\end{array}$ & $\begin{array}{l}\text { Help reduce procedure delays ac- } \\
\text { cording to nurses [18] }\end{array}$ & $\begin{array}{l}\text { 21\% total Increase in endoscopy } \\
\text { procedure completions in Written } \\
\text { et al. study [18] }\end{array}$ \\
\hline
\end{tabular}

To overcome those barriers, various facilitators have been identified to contribute to successful implementation of the gastrointestinal endoscopy checklist. Generally speaking, organizational contextual factors such as departmental culture and leadership and also social and behaviors factors such as professional opinions have had great impact on implementation success [23]. More specifically in our analysis, the adherence rate was significantly increased after implementation of various interventions targeting barriers to checklists. Raphael et al. used remote video auditing (RVA) installed in every endoscopy room to monitor checklist utilization and increase adherence by staff members. Simultaneously, a checklist leader and team education on a specific gastrointestinal checklist were introduced. The quality team also implemented a visual indicator of the checklist, which was a yellow card lifted up by the anesthesiologist at the moment of the "time out". Subsequently, physician checklist compliance increased from $70 \%$ to $95 \%$ [17]. Because time delay often was identified as a barrier to checklist implementation, it is important to note that Raphael et al. also described a concise checklist designed to be completed in only 30 seconds (half the time of completion of the WHO surgical checklist) [17]. However, to the best of our knowledge, no trial has incorporated the checklist directly into the computerized endoscopic report generator, a method that could increase checklist adherence, as suggested by De Vries et al., who interviewed surgeons and anesthesiologist [24]. In addition, Walker et al. found that education and local champions were the cornerstone of successful checklist implementation in the operating room. Champions were defined as leaders, easily accessible and with good persuasion skills who were not necessarily on the senior management team and were convinced of the checklist utility, with the aim of motivating the operating team to adapt to change [19]. Continuous reassessment of the barriers to and delivery of actionable interventions may help further increase the sustainability of a gastrointestinal endoscopy checklist. Raphael et al. observed sustained improvement in checklist compliance over 2 years following implementation of an endoscopy-specific checklist attributable to steps that enhanced a patient safety culture [17]. Similarly, Matharoo et al. also iden- tified checklist training and continued educational activities for participants as facilitators of sustainability [16].

It remains unclear whether checklists are effective in improving patient safety in performance of digestive endoscopy. In the only three articles that evaluated clinical outcomes [9, $10,18]$, no statistically significant differences were noted in mortality, complications or completion rates. Nevertheless, Kherad et al. showed that checklist implementation improves team communication and teamwork significantly $(4.36 \pm 0.78$ vs. $3.79 \pm 1.0 ; P=0.04)$. Because communication errors are the most common cause of AEs in healthcare, this latter finding is of major importance and indeed, better team communication has been shown to be a good proxy for quality and safety in health care $[12,25]$. Furthermore, teamwork and team communication improvements are significantly associated with a decreased rate of complications and even deaths [26, 27]. Future research should aim to elucidate the relationship between gastrointestinal endoscopy checklist use and safety outcomes with adequately powered controlled trials. However, it is most likely not the act of ticking off a checklist that may reduce complications, but rather the performance of the actions it calls for.

Based on this review and the existing checklist literature $[9,10,14,16-18,28]$, we put forward suggestions for gastrointestinal endoscopy checklist items that are listed in > Fig. $\mathbf{3 .}$

As to suggesting a framework for implementation of a gastrointestinal endoscopy checklist, in recent years, QI methods such as plan-do-study-act (PDSA) iterative cycles have been widely used in healthcare improvement $[29,30]$. In the "plan" stage a change aimed at improvement is identified, the "do" stage sees this change tested, while the "study" stage examines the success of the change with the "act" stage identifying adaptations and next steps to inform a new cycle. Effective interventions need to be multifaceted and developed iteratively to adapt to the local context and respond to unforeseen obstacles and unintended effects. The pragmatic principles of PDSA cycles promote the use of a small-scale, iterative approach to test interventions, as this enables rapid assessment and provides flexibility to adapt the change according to feedback to ensure fit-for-purpose solutions are developed [30]. We thus 


\begin{tabular}{l|l|c}
\multicolumn{2}{|l|}{ Endoscopy safety checklist } & \\
\multirow{3}{*}{$\begin{array}{l}\text { SIGN IN } \\
\text { (outside } \\
\text { endoscopic } \\
\text { room) }\end{array}$} & $\begin{array}{l}\text { Patient ID } \\
\text { Consent } \\
\text { Comorbidity risk: allergy, } \\
\text { anticoagulant }\end{array}$ & $\square$ \\
\hline \multirow{4}{*}{$\begin{array}{l}\text { TIME OUT } \\
\text { (just } \\
\text { before scope } \\
\text { insertion) }\end{array}$} & $\begin{array}{l}\text { Team introduction and patient ID } \\
\text { verbally confirmed }\end{array}$ & $\square$ \\
\cline { 2 - 3 } & $\begin{array}{l}\text { Indication for procedure } \\
\text { - correct scope kit } \\
\text { - specific equipment requirement }\end{array}$ & $\square$ \\
\cline { 2 - 3 } & Monitoring (IV Access, $\mathrm{O}_{2}$ sats) & $\square$ \\
\hline \multirow{2}{*}{$\begin{array}{l}\text { SIGN OUT } \\
\text { (end of } \\
\text { procedure) }\end{array}$} & Documentaion & $\square$ \\
\cline { 2 - 3 } & Sampling and Labelling & $\square$ \\
\cline { 2 - 3 } & Follow-up and recommendations & $\square$ \\
\hline
\end{tabular}

Fig. 3 Endoscopy safety checklist. propose an application of PDSA cycles to facilitate implementation of a gastrointestinal endoscopy checklist, as shown in

-Fig. 4.

\section{Conclusion}

Adoption of a gastrointestinal endoscopy checklist is feasible if barriers and facilitators are identified. Apart from the significantly increased perception of team communication, the evidence base concerning the impact of a gastrointestinal checklist on endoscopic process and patient safety outcomes is limited and warrants further study. The design of the checklist and implementation strategy we propose are neither exhaustive nor mandatory; we take the view that every endoscopy unit ought to develop a tool and framework that best works for the team to optimize the promotion of a safety culture and quality improvement in gastrointestinal endoscopy.

\section{Stage 1. PLAN}

I. Identify whether checklist is already used in your Gl endoscopy unit

II. Assemble a team with a team leader ("champion") that has knowledge of the opportunity for improvement

III. Draft an aim statement focalized on an adherence rate $(>80 \%)$ and team communication as safety proxy

IV. Describe current context and identify barriers and facilitators of a checklist implementation strategy (paper use, electronic report etc)

\section{Stage 4. ACT}

I. Reflect on Plan and Outcomes (adherence rate $>80 \%$ and team communication)

II. Identify barriers and facilitators

III. If your team determined the plan resulted in success, standardize the improvement and begin to use it regularly and make ist sustainable

IV. If your team believes a different approach would be more successful, return to Stage I.

Plan, and develop a new and different plan that might result in success

\section{Stage 2. DO}

I. Create your $\mathrm{Gl}$ endoscopy checklist including key safety elements

II. Validate your checklist by integrating several stakeholders and frontline staff and customize it accordingly

III. Plan a period of training and education before implementation

IV. Be sure to collect data as you go, to help you evaluate your plan in stage 3

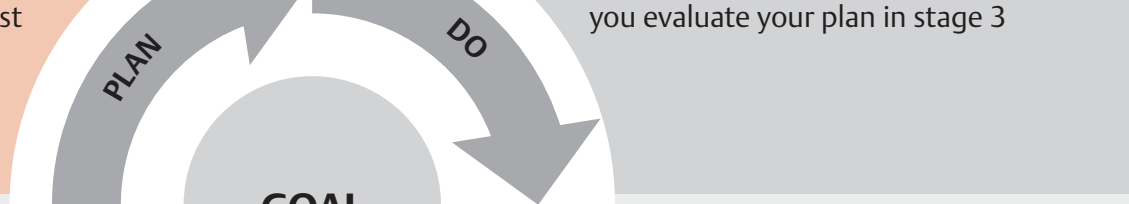

Stage 3. STUDY

I. Audit checklist adoption

II. Use data feedback and a run chart analysis to assess whether the compliance rate is maintained over $80 \%$

III. Use questionnaire in order to assess team communication and patient satisfaction

- Fig. 4 Checklist implementation framework following PDSA cycles. 
Competing interests

The authors declare that they have no conflict of interest.

\section{References}

[1] Kheraj R, Tewani SK, Ketwaroo G et al. Quality improvement in gastroenterology clinical practice. Clin Gastroenterol Hepatol 2012; 10 1305-1314

[2] Rizk MK, Sawhney MS, Cohen J et al. Quality indicators common to all Gl endoscopic procedures. Am J Gastroenterol 2014; 110: 48-59

[3] Crispin A, Birkner B, Munte A et al. Process quality and incidence of acute complications in a series of more than 230,000 outpatient coIonoscopies. Endoscopy 2009; 41: 1018-1025

[4] Gavin DR, Valori RM, Anderson JT et al. The national colonoscopy audit: a nationwide assessment of the quality and safety of colonoscopy in the UK. Gut 2012; 62: 242-249

[5] WHO. The Surgical Safety Checklist. World Health Organisation; 2008: http://www.who.int/patientsafety/safesurgery/tools_resources/SSSL_Checklist_finalJun08.pdf

[6] Haynes AB, Weiser TG, Berry WR et al. A surgical safety checklist to reduce morbidity and mortality in a global population. $N$ Engl J Med 2009; 360: 491-499

[7] Borchard A, Schwappach DL, Barbir A et al. A systematic review of the effectiveness, compliance, and critical factors for implementation of safety checklists in surgery. Ann Surg 2012; 256: 925-933

[8] Ko HC, Turner TJ, Finnigan MA. Systematic review of safety checklists for use by medical care teams in acute hospital settings-limited evidence of effectiveness. BMC Health Ser Res 2011; 11: 211

[9] Dubois H, Schmidt PT, Creutzfeldt J et al. Person-centered endoscopy safety checklist: Development, implementation, and evaluation. World J Gastroenterol 2017; 23: 8605-8614

[10] Kherad O, Restellini S, Ménard C et al. Implementation of a checklist before colonoscopy: a quality improvement initiative. Endoscopy 2017; 50: 203-210

[11] Popay J, Roberts H, Sowden A et al. Guidance on the Conduct of Narrative Synthesis in Systematic Reviews. A Product from the ESRC Methods Programme Im. 2020: https://www.researchgate.net/profile/Mark_Rodgers4/publication/233866356_Guidance_on_the_conduct_of_narrative_synthesis_in_systematic_reviews_A_product_ from_the_ESRC_Methods_Programme/links/02e7e5231e8f 3a6183000000/Guidance-on-the-conduct-of-narrative-synthesis-insystematic-reviews-A-product-from-the-ESRC-Methods-Programme. pdf

[12] Lingard L, Espin S, Whyte $S$ et al. Communication failures in the operating room: an observational classification of recurrent types and effects. Qual Saf Health Care 2004; 13: 330-334

[13] The Newcastle-Ottawa scale (NOS) for assessing the quailty of nonrandomised studies in meta-analyses. 2009: http://www.ohri.ca/programs/clinical_epidemiology/oxford.asp
[14] Coriat R, Lecler A, Lamarque D et al. Quality indicators for colonoscopy procedures: a prospective multicentre method for endoscopy units. PLoS One 2012; 7: e33957

[15] Coriat R, Pommaret E, Chryssostalis A et al. Quality control of colonoscopy procedures: a prospective validated method for the evaluation of professional practices applicable to all endoscopic units. Gastroenterol Clin Biol 2008; 33: 103-108

[16] Matharoo M, Thomas-Gibson S, Haycock A et al. Implementation of an endoscopy safety checklist. Frontline Gastroenterol 2013; 5: 260265

[17] Raphael K, Cerrone S, Sceppa E et al. Improving patient safety in the endoscopy unit: utilization of remote video auditing to improve timeout compliance. Gastrointest Endosc 2019; 90: 424-429

[18] Wittren SP, Cunningham Gregor SR et al. Using performance management to implement a preprocedural checklist for gastrointestinal endoscopy procedures. Gastroenterol Nurs 2019; 42: 79-83

[19] Walker IA, Reshamwalla S, Wilson IH. Surgical safety checklists: do they improve outcomes? Br J Anaesth 2012; 109: 47-54

[20] Pronovost P, Needham D, Berenholtz $S$ et al. An intervention to decrease catheter-related bloodstream infections in the ICU. N Engl J Med 2006; 355: 2725-2732

[21] Fourcade A, Blache JL, Grenier C et al. Barriers to staff adoption of a surgical safety checklist. BMJ Quality Safety 2011; 21: 191-197

[22] Ramanujan R, Keyser DJ, Sirio CA. Making a case for organizational change in patient safety initiatives. In: Advances in Patient Safety: From Research to Implementation. 2005

[23] Kristensen N, Nymann C, Konradsen H. Implementing research results in clinical practice- the experiences of healthcare professionals. BMC Health Services Res 2016; 16: 48

[24] De Vries EN, Hollmann MW, Smorenburg SM et al. Development and validation of the SURgical PAtient Safety System (SURPASS) checklist. Qual Saf Health Care 2009; 18: 121-126

[25] Sewell M, Adebibe M, Jayakumar P et al. Use of the WHO surgical safety checklist in trauma and orthopaedic patients. Int Orthop 2010; 35: 897-901

[26] Mazzocco K, Petitti DB, Fong KT et al. Surgical team behaviors and patient outcomes. Am J Surg 2008; 197: 678-685

[27] Dellinger EP. Teamwork and collaboration for prevention of surgical site infections. Surg Infect (Larchmt) 2016; 17: 198-202

[28] Weiser TG, Haynes AB, Lashoher A et al. Perspectives in quality: designing the WHO Surgical Safety Checklist. Int J Qual Health Care 2010; $22: 365-370$

[29] Nicolay CR, Purkayastha S, Greenhalgh A et al. Systematic review of the application of quality improvement methodologies from the manufacturing industry to surgical healthcare. Br J Surg 2012; 99: 324-335

[30] Taylor M], McNicholas C, Nicolay C et al. Systematic review of the application of the plan-do-study-act method to improve quality in healthcare. BMJ Quality Safety 2014; 23: 290-298 